Article

\title{
Capsaicin Inhibits Multiple Bladder Cancer Cell Phenotypes by Inhibiting Tumor-Associated NADH Oxidase (tNOX) and Sirtuin1 (SIRT1)
}

\author{
Ming-Hung Lin ${ }^{1,2}$, Yi-Hui Lee ${ }^{1}$, Hsiao-Ling Cheng ${ }^{1}$, Huei-Yu Chen ${ }^{1}$, Fong-Han Jhuang ${ }^{1}$ and \\ Pin Ju Chueh 1,3,4,5,* \\ 1 Institute of Biomedical Sciences, National Chung Hsing University, Taichung 40227, Taiwan; \\ w101052018@gmail.com (M.-H.L.); cornsugar@gmail.com (Y.-H.L.); hikki4028@yahoo.com.tw (H.-L.C.); \\ trista09081123@gmail.com (H.-Y.C.); s7213987@gmail.com (F.-H.J.) \\ 2 Tainan Municipal An-Nan Hospital, China Medical University, Tainan 70965, Taiwan \\ 3 Graduate Institute of Basic Medicine, China Medical University, Taichung 40402, Taiwan \\ 4 Department of Medical Research, China Medical University Hospital, Taichung 40402, Taiwan \\ 5 Department of Biotechnology, Asia University, Taichung 41354, Taiwan \\ * Correspondence: pjchueh@dragon.nchu.edu.tw; Tel.: +886-4-2284-0896; Fax: +886-4-2285-3469
}

Academic Editor: Derek J. McPhee

Received: 29 April 2016; Accepted: 24 June 2016; Published: 28 June 2016

\begin{abstract}
Bladder cancer is one of the most frequent cancers among males, and its poor survival rate reflects problems with aggressiveness and chemo-resistance. Recent interest has focused on the use of chemopreventatives (nontoxic natural agents that may suppress cancer progression) to induce targeted apoptosis for cancer therapy. Capsaicin, which has anti-cancer properties, is one such agent. It is known to preferentially inhibit a tumor-associated NADH oxidase (tNOX) that is preferentially expressed in cancer/transformed cells. Here, we set out to elucidate the correlation between tNOX expression and the inhibitory effects of capsaicin in human bladder cancer cells. We showed that capsaicin downregulates tNOX expression and decreases bladder cancer cell growth by enhancing apoptosis. Moreover, capsaicin was found to reduce the expression levels of several proteins involved in cell cycle progression, in association with increases in the cell doubling time and enhanced cell cycle arrest. Capsaicin was also shown to inhibit the activation of ERK, thereby reducing the phosphorylation of paxillin and FAK, which leads to decreased cell migration. Finally, our results indicate that RNA interference-mediated tNOX depletion enhances spontaneous apoptosis, prolongs cell cycle progression, and reduces cell migration and the epithelial-mesenchymal transition. We also observed a downregulation of sirtuin 1 (SIRT1) in these tNOX-knockdown cells, a deacetylase that is important in multiple cellular functions. Taken together, our results indicate that capsaicin inhibits the growth of bladder cancer cells by inhibiting tNOX and SIRT1 and thereby reducing proliferation, attenuating migration, and prolonging cell cycle progression.
\end{abstract}

Keywords: apoptosis; cancer; capsaicin; silent mating type information regulation 1 (sirtuin1, SIRT1); tumor-associated NADH oxidase (tNOX; ENOX2)

\section{Introduction}

According to the cancer incidence and mortality estimates for 2012, bladder cancer was the sixth most frequent type of cancer among males and the ninth leading cause of death worldwide [1]. Although most patients are initially diagnosed with non-muscle-invasive bladder cancer, many such tumors recur after therapy and eventually exhibit muscle invasion [2]. Cancer is multistage process with a complex etiology. However, the concept of using nontoxic natural compounds to reduce carcinogenesis (called chemoprevention) has emerged as a strategy. Researchers have also recently 
focused on using such agents against cancer cells to induce apoptosis, which represents a programmed self-killing mechanism that involves extrinsic and intrinsic pathways [3-6]. In bladder cancer cells, apoptosis is reportedly induced by the ethanol extract of pomegranate fruits [7], the green tea catechin, EGCg [8], grape seed extract [9], and resveratrol [10].

Here, we focused on an active component of chili pepper, capsaicin (8-methyl- $N$-vanillyl-6nonenamide), which has shown in vitro inhibitory effects on many cancer cell lines [11-15]. The various signaling pathways known to be involved in capsaicin-mediated cellular responses include oxidative stress, which is known to trigger apoptosis [16-19]. Indeed, capsaicin was shown to induce apoptosis in pancreatic cancer cells in association with reactive oxygen species (ROS) generation and mitochondrial damages $[19,20]$. However, other pathways are also relevant to capsaicin-mediated apoptosis. Nitric oxide (NO) elevation was found to be induced by capsaicin in association with Mdm2 down-regulation and p53 activation, thereby increases the apoptotic Bax expression and mitochondrial-dependent apoptosis [21]. Capsaicin also exerts its inhibitory effect on the activation of STAT3 in multiple myeloma cells, in turn alters protein expression of $\mathrm{Bcl}-2, \mathrm{Bcl}-\mathrm{xL}$, and survivin, resulting in apoptosis [22].

We previously demonstrated that capsaicin preferentially targets a tumor-associated $\mathrm{NADH}$ oxidase (tNOX) in cancer/transformed cells, thereby enhancing ROS generation and apoptosis $[11,12,23,24]$. tNOX belongs to a family of growth-related plasma membrane hydroquinone oxidases that are responsible for converting reduced NADH to the oxidized $\mathrm{NAD}^{+}$form [25]. The results from gain- and loss-of-function experiments consistently show a close correlation between tNOX expression and aggressive cancer phenotypes [26,27]. Given that tNOX is associated with cancer phenotypes and is preferentially inhibited by capsaicin, the molecular mechanisms underlying its anticancer properties are of great interest. Capsaicin-mediated ROS overproduction parallels the inhibition of $\mathrm{tNOX}$, suggesting that the latter contributes to the cytotoxicity of capsaicin and might even be an upstream regulator of the intracellular redox homeostasis [12]. In addition, we recently reported that capsaicin diminishes the intracellular $\mathrm{NAD}^{+} / \mathrm{NADH}$ ratio through inhibition of $\mathrm{tNOX}$ and subsequent reduction of the $\mathrm{NAD}^{+}$-dependent deacetylase, sirtuin 1 deacetylase (SIRT1), which increases p53 acetylation and apoptosis [28]. However, whether tNOX/SIRT1 axis affects cellular functions other than apoptosis has not been examined before.

Here, we present evidence demonstrating that capsaicin-induced tNOX suppression reduces multiple cancer phenotypes in human cancer cells. We further confirm that, for the first time, the downregulation of tNOX concurrently with decreased SIRT1 contribute to the reduced cancer phenotypes, including enhanced apoptosis, increased cell doubling time, and decreased cell migration.

\section{Results}

\subsection{Capsaicin Downregulates tNOX and Inhibits TSGH8301 Cell Growth by Induction of Mitochondria-Dependent Apoptosis}

Capsaicin is found to inhibit tNOX expression in various cancer cell lines, but not in bladder cancer cells. In this study, we found that capsaicin treatment at 100 and $200 \mu \mathrm{M}$ effectively reduced tNOX expression in bladder cancer TSGH8301 (herein called TSGH) and T24 cells (Figure 1A). As previous studies suggested that tNOX downregulation is associated with reduced cell growth [23,24,27], we monitored the growth of capsaicin-exposed cells by cell impedance measurements. We found that cell growth (presented as normalized cell index values) of TSGH cells was inhibited by 100 and $200 \mu \mathrm{M}$, and that of T24 was somewhat reduced by $10 \mu \mathrm{M}$ of capsaicin (Figure 1B). This cell growth inhibition was accompanied by enhanced apoptosis in TSGH cells treated with 100 and $200 \mu \mathrm{M}$ capsaicin (Figure 2A). To begin dissecting the underlying mechanisms of this apoptosis, we examined oxidative stress by $\mathrm{H}_{2}$ DCFDA staining and found that capsaicin dose-dependently increased ROS generation (Figure 2B). JC-10 staining showed that this triggered changes in mitochondrial membrane potential (Figure 2C). 
A.
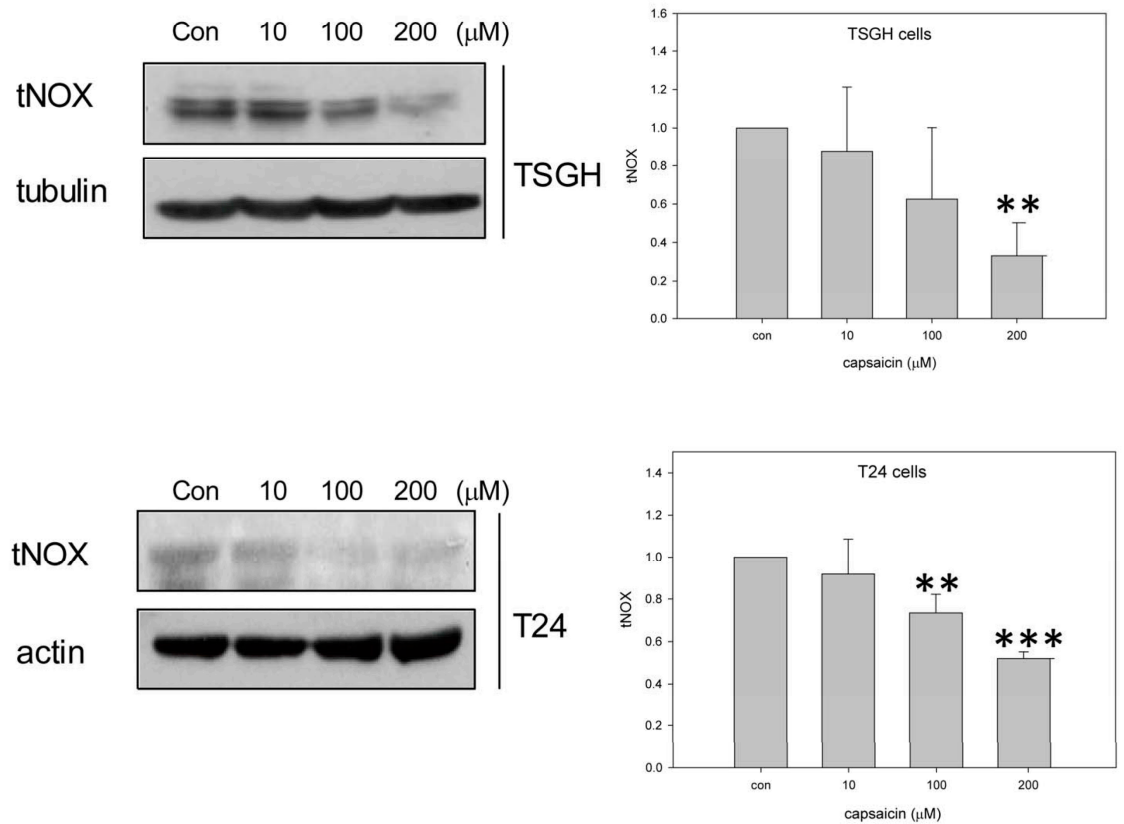

B.
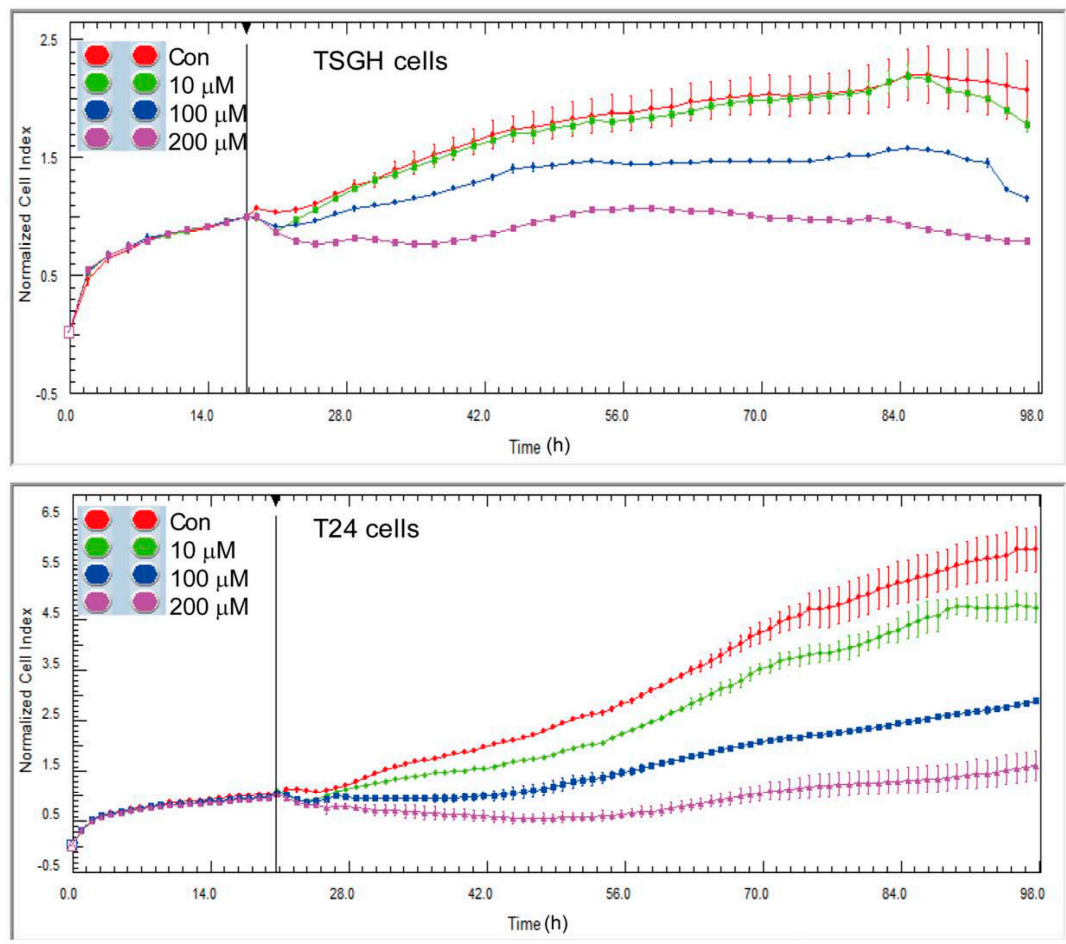

Figure 1. Capsaicin downregulates tNOX expression and inhibits cell growth in TSGH8301 (herein called TSGH) and T24 cells. (A) Cells were treated with capsaicin or ethanol for $18 \mathrm{~h}$. Aliquots of cell lysates were separated by SDS-PAGE and analyzed by western blotting; $\beta$-actin (or tubulin) was used as an internal control. Representative images from four experiments are shown. The intensity of a protein band was quantified by Gel-Pro Analyzer software 3.1. The resultant values of protein expression were normalized to those of actin. Values (mean $\pm \mathrm{SE}$ ) are from three independent experiments $\left({ }^{* *} p<0.01\right.$, $* * *<0.001)$; (B) Cell growth with or without capsaicin was dynamically monitored using impedance technology. Normalized cell index values measured over $96 \mathrm{~h}$ are shown. 

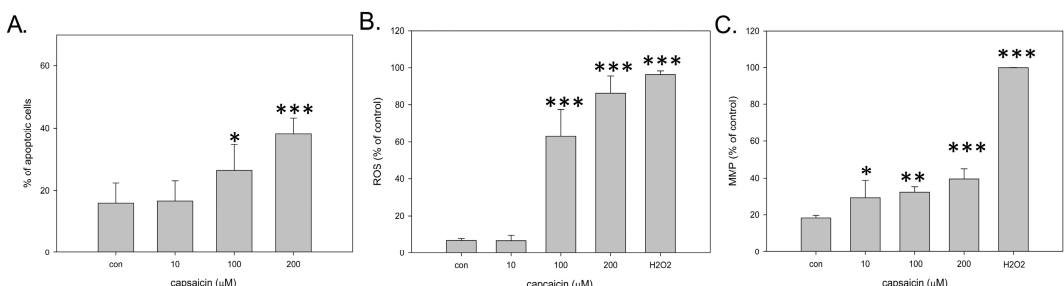

D.

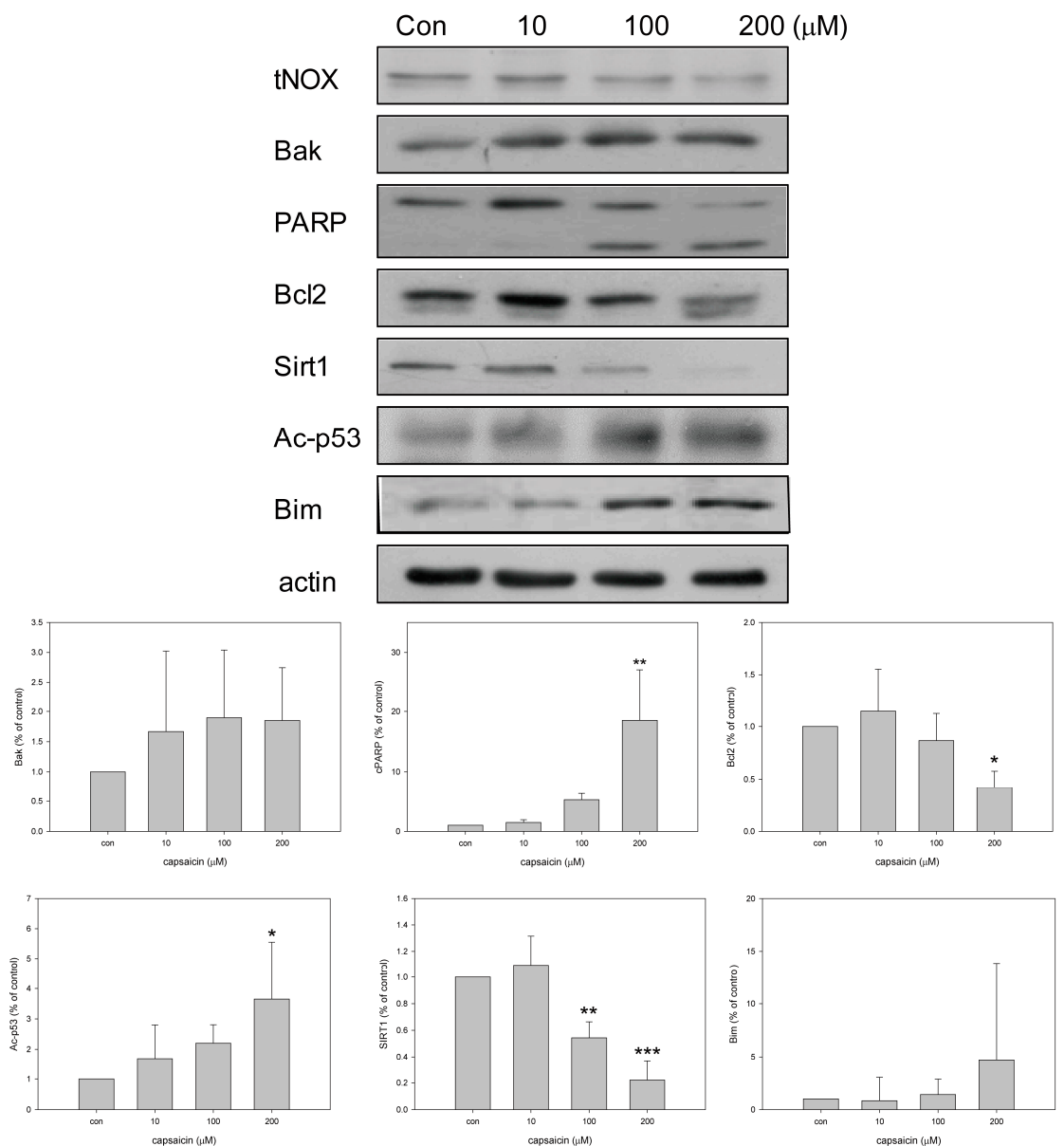

Figure 2. Capsaicin induces mitochondria-dependent apoptosis in TSGH cells. (A) Cells were treated with ethanol or capsaicin for $18 \mathrm{~h}$. The distribution of viable (FITC/PI double-negative), early apoptotic (FITC-positive), late apoptotic (FITC/PI double-positive) and necrotic (PI-positive/FITC-negative) cells was analyzed using a Beckman Coulter FC500 flow cytometer. Both early and late apoptotic cells are included in our definition for apoptosis. Values (mean \pm SE) are from three independent experiments $\left(* p<0.05,{ }^{* * *} p<0.001\right.$, for cells treated with capsaicin vs. controls by one-way ANOVA with LSD); (B) Cells were treated with ethanol or capsaicin for $6 \mathrm{~h}$. ROS generation was assessed by flow cytometric analysis of $\mathrm{H}_{2}$ DCFDA in TSGH cells and is expressed as a percentage of cells. Values (mean $\pm \mathrm{SE}$ ) are from four independent experiments ${ }^{* * *} p<0.001$, for cells treated with capsaicin vs. controls by one-way ANOVA with LSD); (C) Cells were treated with capsaicin or ethanol for $3 \mathrm{~h}$. Mitochondrial function was assessed by flow cytometric analysis of JC-10 in TSGH cells and is expressed as a percentage of cells. Values (mean $\pm \mathrm{SE}$ ) are from four independent experiments $\left({ }^{*} p<0.05,{ }^{* *} p<0.01,{ }^{* * *} p<0.001\right.$, for cells treated with capsaicin vs. controls by one-way ANOVA with LSD); (D) Aliquots of cell lysates were separated by SDS-PAGE and analyzed by Western blotting; $\beta$-actin was used as an internal control. Representative images are shown. The intensity of a protein band was quantified by Gel-Pro Analyzer software 3.1The resultant values of protein expression were normalized to those of actin. Values (mean $\pm \mathrm{SE}$ ) are from three independent experiments $\left({ }^{*} p<0.05\right.$, ** $\left.p<0.01,{ }^{* * *} p<0.001\right)$. 
Moreover, protein analysis demonstrated that capsaicin downregulated the pro-survival protein, Bcl2, while upregulating the pro-apoptotic protein, Bak, and enhancing the caspase3-medaited cleavage of PARP (Figure 2D). In this study, we also confirmed the effect of capsaicin on SIRT1 deacetylase in TSGH cells, and found that 100 and $200 \mu \mathrm{M}$ capsaicin decreased SIRT1 expression and concurrently increased p53 acetylation (Figure 2D).

Previous studies suggest that SIRT1 negatively regulates the expression of the tumor suppressor, FOXO3 [29], and FOXO3 is a key transcription factor for upregulation of the apoptotic protein Bim [30]. Consistent with these, we observed that capsaicin treatments (i.e., SIRT1 downregulation) enhanced the expression level of Bim (Figure 2D).

\subsection{Capsaicin Downregulates $t$ NOX and Induces Cell Cycle Arrest at G1 Phase}

To further assess the anti-proliferative effect of capsaicin, we examined changes in the cell cycle distributions. Western blot analyses revealed that capsaicin downregulated tNOX expression, and further revealed downregulation of phosphorylated $\mathrm{Rb}$ and cyclin $\mathrm{D}$, which are involved in cell cycle progression (Figure 3A). Cell cycle determination also confirmed that capsaicin significantly enhanced cell arrest at G1 phase at 100 and $200 \mu \mathrm{M}$ (Figure 3B).

A.

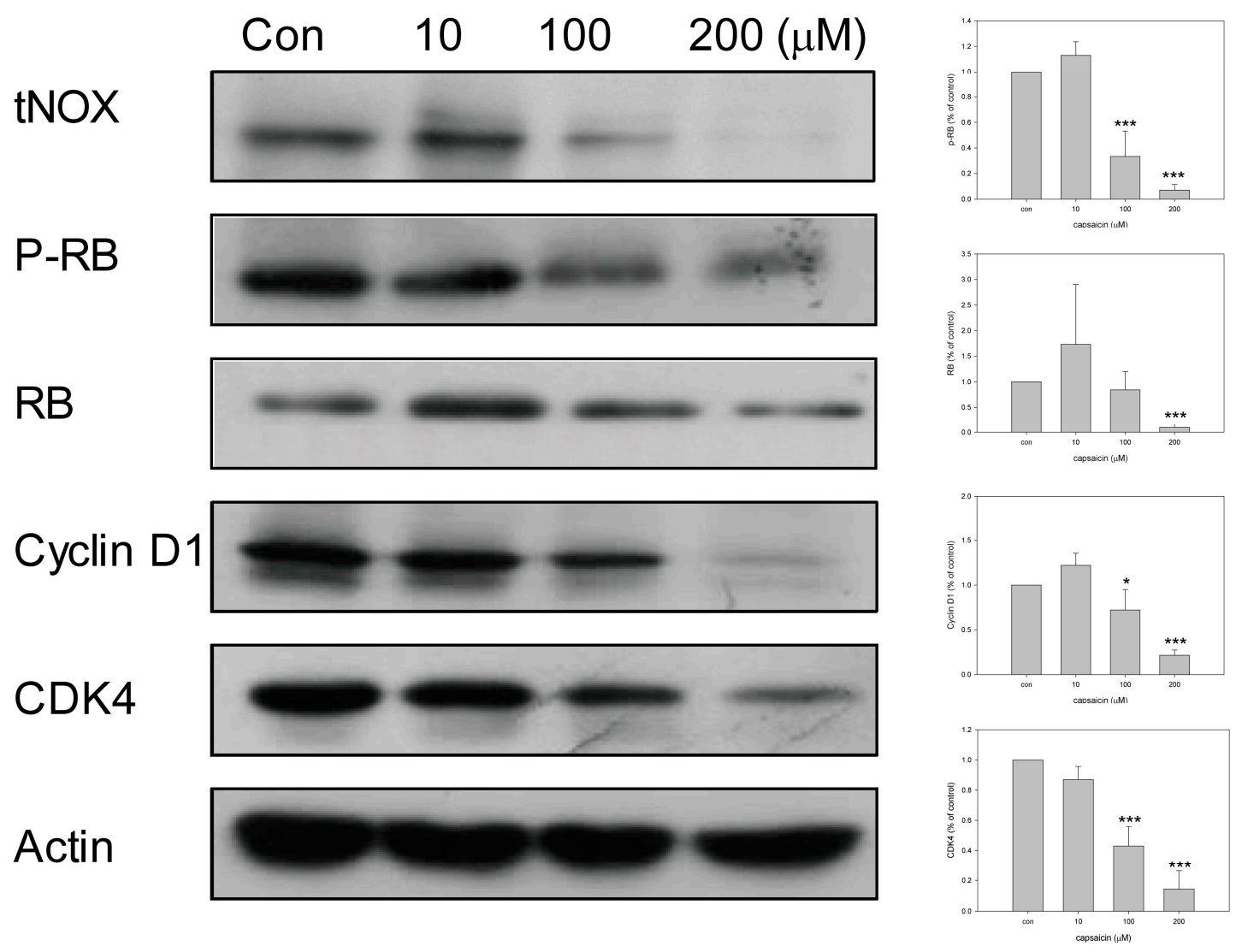

Figure 3. Cont. 
B.

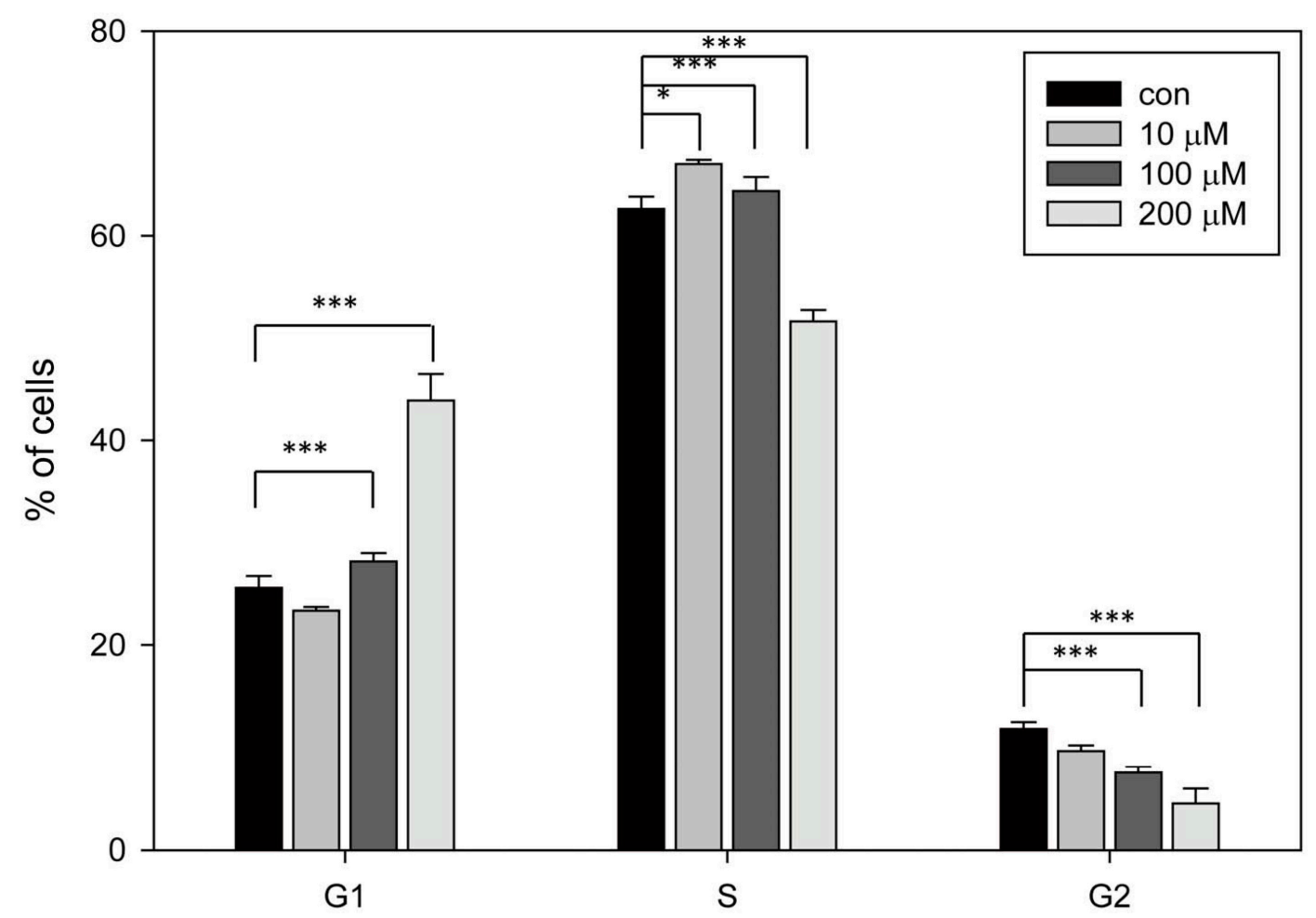

Figure 3. Capsaicin induces cell cycle arrest. TSGH cells were treated with capsaicin or ethanol for $18 \mathrm{~h}$. (A) Aliquots of cell lysates were separated by SDS-PAGE and analyzed by western blotting. $\beta$-actin was used as an internal control. The intensity of a protein band was quantified by Gel-Pro Analyzer software 3.1. The resultant values of protein expression were normalized to those of actin. Values (mean \pm SE) are from three independent experiments (*** $p<0.001)$; (B) Cells were assayed for cell cycle phase. The graphs are representative of three independent experiments. Values (mean $\pm \mathrm{SE}$ ) are from three independent experiments. The percentage of cells in G1 phase was significantly higher in cells treated with 100 and $200 \mu \mathrm{M}$ capsaicin compared to cells in the control group by one-way ANOVA with LSD $\left({ }^{*} p<0.05,{ }^{* * *} p<0.001\right)$.

\subsection{Capsaicin Downregulates tNOX and Reduces Cell Migration}

Given that gain- and loss-of-function approaches showed that the expression level of tNOX is relevant to cell migration [27,31], we used cell impedance measurements to examine the effect of capsaicin on the migration of bladder cancer cells. We found that 100 and $200 \mu \mathrm{M}$ capsaicin effectively attenuated cell migration in both TSGH cells and T24 cell lines (Figure 4A). Interestingly, cell migration was somewhat increased with $10 \mu \mathrm{M}$ accompanied by up-regulation of tNOX expression, that is consistent with our previous findings in HCT116 cells [32]. Mechanistically, 100 and $200 \mu \mathrm{M}$ capsaicin inhibited ERK downstream targets, paxillin and FAK, which are all important for cell migration regulation (Figure 4B). The attenuated cell migration was also associated with the downregulation of transcription factors $\beta$-catenin, leading to a decrease in mesenchymal marker $\mathrm{N}$-cadherin and an increase in epithelial marker E-cadherin (Figure 4B). 
A.
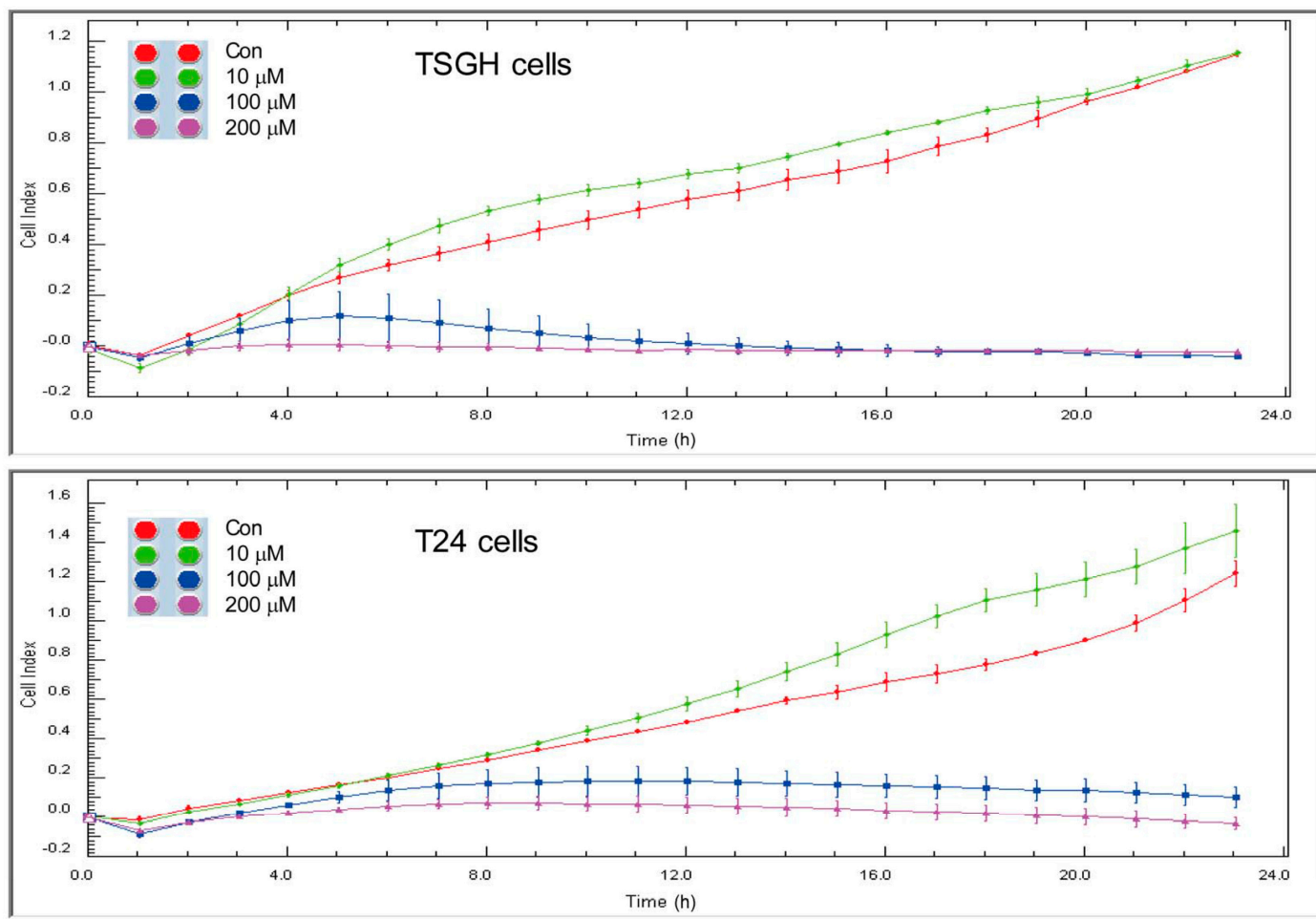

B.

TSGH
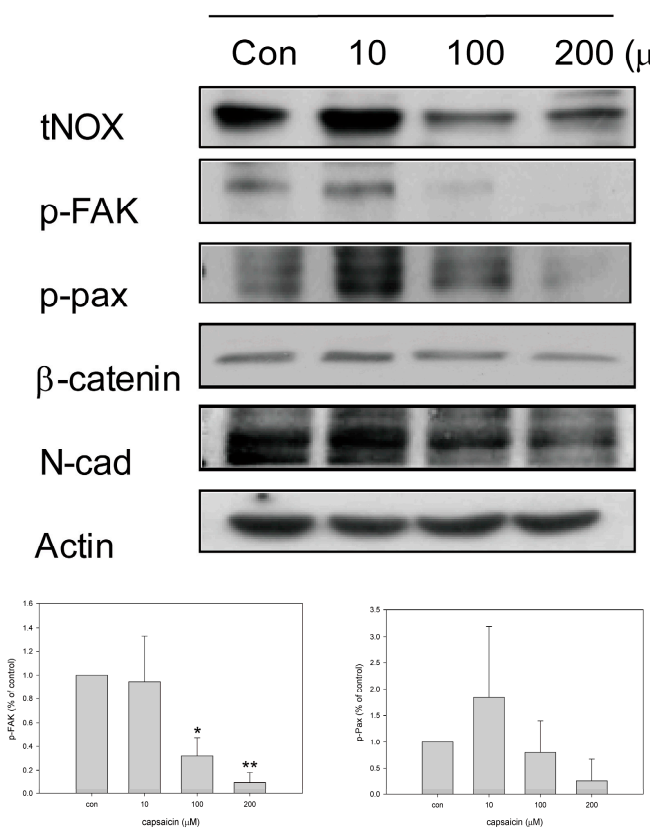

T24
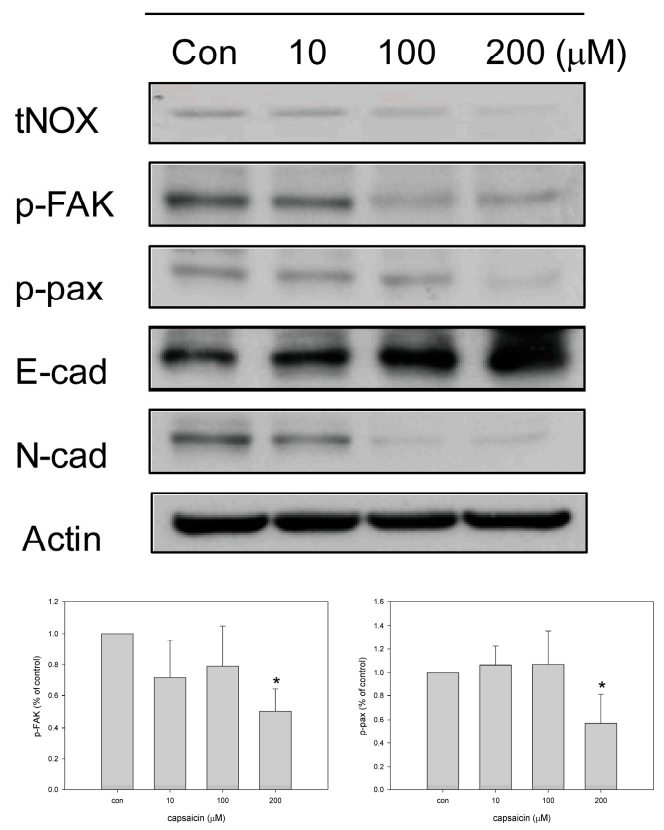

Figure 4. Capsaicin attenuates cell migration. (A) Dynamic monitoring of cell migration using impedance technology, as described in Materials and Methods. Shown are normalized cell index measured over $23 \mathrm{~h}$; (B) Cells were treated with capsaicin or ethanol for $18 \mathrm{~h}$. Aliquots of cell lysates were separated by SDS-PAGE and analyzed by western blotting. $\beta$-actin was used as an internal control. The intensity of a protein band was quantified by Gel-Pro Analyzer software 3.1. The resultant values of protein expression were normalized to those of actin. Values (mean $\pm \mathrm{SE}$ ) are from three independent experiments $\left({ }^{*} p<0.05,{ }^{* *} p<0.01\right)$. 


\subsection{RNA Interference-Mediated tNOX Depletion Reverses Cancer Phenotypes}

Next, we used RNA interference to examine whether tNOX is essential for cancer phenotypes of TSGH cells. Indeed, tNOX depletion was found to significantly increase spontaneous apoptosis (Figure 5A), increase the doubling time (Figure 5B), and decrease cell migration (Figure 5C). We also observed downregulation of SIRT1 in these tNOX-knockdown cells (Figure 5D). The results from protein analyses (Figure 5D) further supported the notion that tNOX knockdown-mediated SIRT1 downregulation reduces the cancer phenotypes of these cultured bladder cancer cells, demonstrating an increase in levels of Bim, caspase 3-direct PARP cleavage, and p53 (enhanced apoptosis), changes in levels of cyclin D, CDK4, and p21 (prolonged cell cycle progression), an increase in E-cadherin while FAK and slug are downregulated (attenuated cell migration).

A.

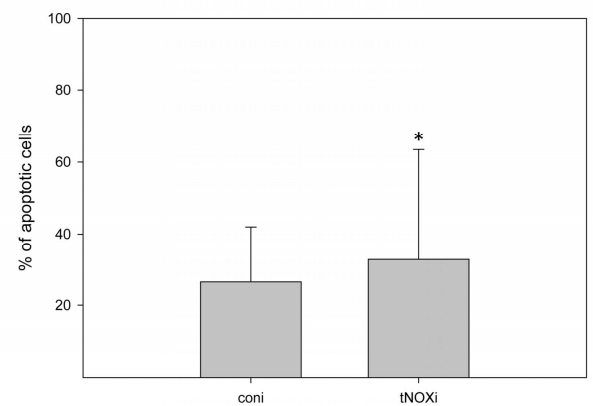

B.

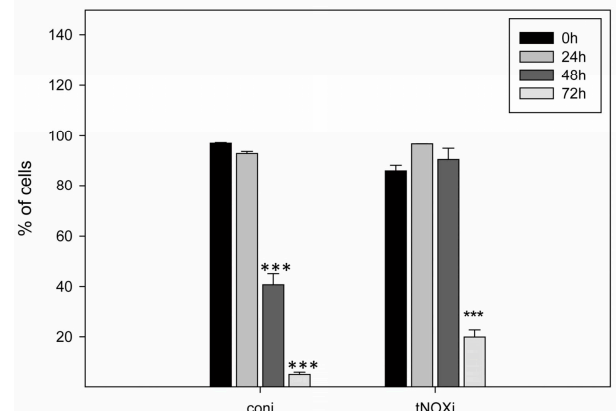

D.

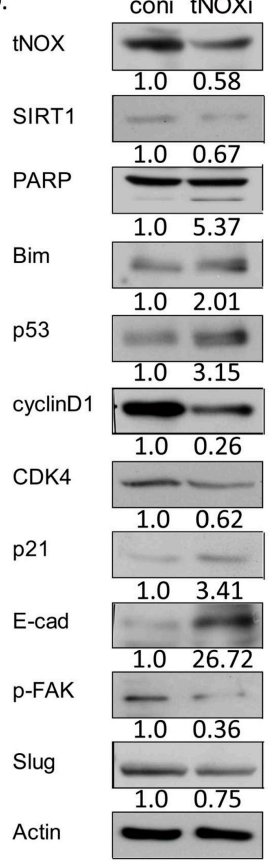

C.

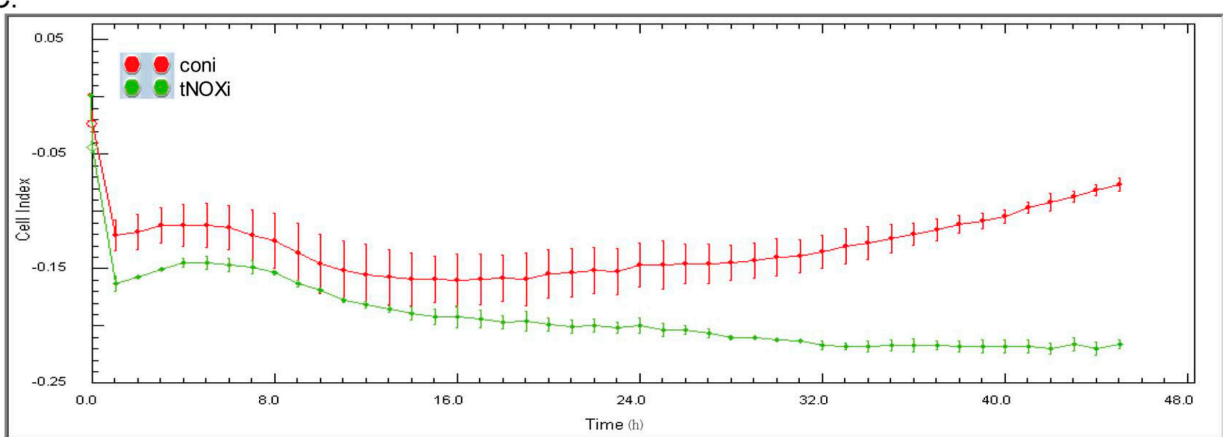

Figure 5. The siRNA-mediated knockdown of $t$ NOX suppresses multiple cancer phenotypes. tNOX was down-regulated by siRNA, and cells were assayed for various cellular functions. (A) The percentage of apoptotic cells was determined by flow-cytometry, and the results are expressed as a percentage of apoptotic cells. Values (mean $\pm \mathrm{SE}$ ) are from three independent experiments by $t$-test $\left({ }^{*} p<0.05\right)$; (B) Cell division was analyzed by CMFDA staining of tNOX-knockdown and control cells. The presented values (mean $\pm \mathrm{SE}$ ) represent at least three independent experiments by one-way ANOVA with LSD ( $\left.{ }^{*} p<0.05\right)$; (C) Dynamic monitoring of cell migration using impedance technology, as described in Materials and Methods. Shown are normalized cell index measured over 45 h; (D) Aliquots of cell lysates were separated by SDS-PAGE and analyzed by western blotting; $\beta$-actin was used as an internal control. Representative images from three experiments are shown. 


\section{Discussion}

Among the various signaling pathways involved in capsaicin-mediated cellular responses, oxidative stress has received research attention because it leads to apoptosis [16-19]. Although mitochondrial ROS generation is thought to be the major source of cellular oxidative stress, other sources may factor into capsaicin-induced apoptosis. For example, the suppression of cyclooxygenase (COX), a ROS-generating enzyme, was shown to be involved in capsaicin-induced apoptosis of human neuroblastoma cells [33]. The plasma membrane-resident NADPH oxidase also responds to capsaicin, and the ROS generated by this enzyme are essential to the capsaicin-induced apoptosis of HepG2 human hepatoblastoma cells [18]. Furthermore, capsaicin exerts its apoptotic activity through overexpression of transient receptor potential vanilloid type 1 (TRPV1), the most-often mentioned cationic channel protein targets of capsaicin, in urothelial carcinoma cells [34,35]. The capsaicin-mediated TRPV1 activation also generates ROS production, mitochondrial dysfunction, and apoptosis in T24 cells [36]. In this study, we present evidence demonstrating that tNOX contributes to capsaicin-mediated apoptosis and is important for capsaicin-induced suppression of cancer phenotypes. Given that tNOX catalyzes the oxidation of NADH to oxidized NAD ${ }^{+}$, the depletion of $\mathrm{tNOX}$ reduces $\mathrm{NAD}^{+}$generation and attenuates $\mathrm{NAD}^{+}$-dependant SIRT1 deacetylase activity, which is involved in an array of cellular functions, is equally important for capsaicin-induced enrichment in apoptosis and suppression of cell proliferation and migration and apoptosis.

SIRT1, which belongs to the sirtuin protein family, is well conserved in all species and is thought to be involved in cellular functions ranging from epigenetic regulation to metabolism and stress response [37]. The deacetylase activity of SIRT1 on p53 has emerged as a major regulator of apoptosis in stressed cells [38,39]. However, the effect of capsaicin on SIRT1 had not been thoroughly examined in previous studies. We recently reported that capsaicin decreases the intracellular $\mathrm{NAD}^{+} / \mathrm{NADH}$ ratio, thereby reducing SIRT1 activity and p53 acetylation, and ultimately triggering apoptosis in A549 human lung cancer cells [28]. Here, we report that capsaicin-mediated tNOX suppression and experimental knockdown of $t$ NOX reduce SIRT1 expression in a bladder cancer cell line. It has been suggested that SIRT1 is negatively regulated by microRNAs-34a, and that p53 enhances microRNA-34a expression to promote apoptosis [40,41]. Although not yet thoroughly tested in this system, we speculate that the activation of p53 by capsaicin exposure or $\mathrm{tNOX}$ depletion might upregulatemicroRNA-34a, and that this might lead to SIRT1 downregulation. Our results also showed that the apoptotic and downstream target of FOXO3 (a renowned downstream target for SIRT1), is enhanced in capsaicin-exposed TSGH cells. Consistent with our results, Wang et al. have reported that FOXO3-induced Bim upregulation is essential for traditional Chinese medicine rhubarb-mediated apoptosis [30].

Our functional and protein assays showed that the capsaicin-induced attenuation of SIRT1 was correlated with reduced cell migration. It was previously reported that the SIRT1 upregulation induced by the carcinogen benzo[a]pyrene $(\mathrm{B}[\mathrm{a}] \mathrm{P})$, was associated with the upregulation of $\beta$-catenin, which drives cell migration, invasion, and even tumorgenesis [42]. Furthermore, the reduced paxillin phosphorylation by ERK inactivation was reported to significantly inhibit cell spreading and migration [43]. Consistent with these, we found that $t$ NOX knockdown possibly affected ERK activation leading to reduced levels of ERK downstream targets, paxillin and FAK, perhaps explaining the observed attenuation of cell migration. Our findings suggest that the reduced SIRT1 expression by tNOX knockdown was found to reduce various cancer phenotypes, and this phenomenon is similar to the way in which sphingosine kinase 1 (Sphk1) and S1P upregulate SIRT1 expression to enhance cell proliferation and migration [44]. Thus, the capsaicin-induced alteration of $t$ NOX and subsequent impact on SIRT1 may exert important effects on multiple cellular pathways. Unfortunately, utilizing capsaicin as an effective cancer strategy has its limitation due to low bioavailability. Thus, it is important to modify, design, or identify new compounds that target tNOX and possess higher bioavailability.

Taken together, our present results show that capsaicin mediates diverse inhibitory effects on the cancer phenotypes of bladder cancer cells, and demonstrate that tNOX depletion exerts similar effects. 
Furthermore, we provide evidence demonstrating that the capsaicin-induced downregulation of $\mathrm{tNOX}$ reduces the expression of SIRT1, which could logically explain the capsaicin-induced deteriorations in multiple cancer phenotypes, including apoptosis, cell cycle progression, and cell migration.

\section{Materials and Methods}

\subsection{Cell Culture and Reagents}

Capsaicin with purity above 95\% was purchased from Sigma-Aldrich Corporation (St. Louis, MO, USA). Anti-Bax, anti-Bak, anti-PARP, anti-Bcl-2, anti-p53, anti-phospho-ERK, anti-Bim, anti-phospho- $\mathrm{Rb}$, anti- $\mathrm{Rb}$, anti-Slug, anti-phospho-paxillin, anti-beta-catenin, anti-cyclinD1, anti-p21, anti-acetyl-p53, and anti-SIRT1 antibodies were from Cell Signaling Technology, Inc. (Beverly, MA, USA). Anti-E-cadherin and anti-N-cadherin antibodies were from BD Pharmingen (San Jose, CA, USA). Anti-CDK4 antibody was purchased from Santa Cruz Biotechnology, Inc. (Santa Cruz, CA, USA). Anti-phospho-FAK antibody was from EnoGene Biotech Co, Ltd. (New York, NY, USA). Anti- $\beta$-actin antibody was from Millipore Corp. (Temecula, CA, USA). Antisera to tNOX were generated as described previously [27]. Other chemicals were from Sigma-Aldrich Corporation.

TSGH8301 human bladder carcinoma cells were grow in DMEM and T24 human bladder carcinoma cells were grown in RPMI. Media were supplemented with $10 \% \mathrm{FBS}, 100 \mathrm{U} / \mathrm{mL}$ penicillin and $50 \mu \mathrm{g} / \mathrm{mL}$ streptomycin. Cells were maintained at $37^{\circ} \mathrm{C}$ in a $5 \% \mathrm{CO}_{2}-95 \%$ air-humidified incubator. ON-TARGET plus tNOX (ENOX2) siRNA and negative control siRNA were purchased from Thermo Scientific, Inc. (Grand Island, NY, USA). Briefly, cells were seeded in 10-cm dishes and allowed to attach overnight. The next day, cells were transfected with tNOX siRNA and control siRNA using Lipofectamin RNAiMAX Reagent (Life Technologies, Grand Island, NY, USA) according to the manufacturer's instructions [45].

\subsection{Cell Impedance Measurements}

Cell impedance technology was used to continuously monitor changes in cell growth. Cells $\left(10^{4}\right.$ per well) were seeded onto E-plates and incubated for $30 \mathrm{~min}$ at room temperature. The E-plates were placed onto the Real-Time Cell Analysis (RTCA) station (xCELLigence System, Roche, Mannhein, Germany), and the cells were grown overnight before exposed to ethanol or different concentrations of capsaicin and cell impedance was measured every hour, as previously described [31].

For continuous monitoring of cell migration, cells $\left(2 \times 10^{4}\right.$ per well) were seeded onto the top chamber of a cell invasion and migration (CIM) plate, which features microelectronic sensors integrated on the underside of the microporous polyethylene terephthalate (PET) membrane of a Boyden-like chamber. After incubation for $30 \mathrm{~min}$ at room temperature, the CIM plates were placed onto the RTCA station. Cell migration was continuously monitored based on changes in the electrical impedance at the electrode/cell interface.

\subsection{Apoptosis Determination}

Annexin V-FITC Apoptosis Detection Kits were used to determine apoptosis (BD Pharmingen). Briefly, cells treated with ethanol or different concentrations of capsaicin were harvested by centrifugation after trypsinization. Cell pellet was washed with PBS and resuspended in $1 \times$ binding buffer. Next, cell pellet was stained with annexin V-FITC (fluorescein isothiocyanate) and also propidium iodide (PI) according to manufacturer's protocol. The patterns of cell death (necrosis and apoptosis) were analyzed using a Beckman Coulter FC500 flow cytometer and results were expressed as a percentage of total cells.

\subsection{Measurement of Changes in the Mitochondrial Membrane Potential}

Changes in the mitochondrial membrane potential were determined by JC-10 staining according to the manufacturer's instructions. Briefly, cells were exposed to capsaicin for $3 \mathrm{~h}$, incubated with 
$10 \mu \mathrm{M} \mathrm{JC}-10$ for $30 \mathrm{~min}$ at $37^{\circ} \mathrm{C}$, and then washed with PBS twice. The changes in the mitochondrial membrane potential were analyzed using a Beckman Coulter FC500 flow cytometer and results were expressed as a percentage of total cells.

\subsection{Cell Division Assay}

RNA interference-targeted tNOX knockdown cells and negative control siRNA-treated cells were labeled by incubating with $5 \mu \mathrm{M}$ CellTracker Green CMFDA (5-chloromethylfluorescein diacetate; Molecular Probes, Eugene, OR, USA) in fresh medium for $45 \mathrm{~min}$. After treatment, the cells were washed with PBS and trypsinized, and cell division was assessed by flow cytometry as previously described [46].

\subsection{Measurement of Oxidative Stress}

Oxidative stress was determined by measuring the level of hydrogen peroxide generated in the cells with the staining method of 5-(and-6)-carboxy-2 $2^{\prime}, 7^{\prime}$-dichlorodihydrofluorescein diacetate (carboxy- $\mathrm{H}_{2} \mathrm{DCFDA}$ ). The basis for this assay is that the nonpolar, nonionic $\mathrm{H}_{2}$-DCFDA is cell permeable and is hydrolyzed to nonfluorescent $\mathrm{H}_{2}$-DCF by intracellular esterases. In the presence of peroxide, $\mathrm{H}_{2}$-DCF is rapidly oxidized to highly fluorescent DCF. At the end of capsaicin treatment, cells $\left(2 \times 10^{5}\right)$ were washed with PBS and incubated with $5 \mu \mathrm{M} \mathrm{H}_{2}$ DCFDA in DMSO for $30 \mathrm{~min}$. Cells were collected by trypsinization and centrifugation, washed with PBS, centrifuged at $200 \times g$ for 5 min and analyzed immediately using a Beckman Coulter FC500 flow cytometer as previously reported [47].

\subsection{Western Blot Analysis}

Cell extracts were prepared in lysis buffer containing $20 \mathrm{mM}$ Tris-HCl pH 7.4, $100 \mathrm{mM} \mathrm{NaCl}, 5 \mathrm{mM}$ EDTA, $2 \mathrm{mM}$ phenylmethylsulfonyl fluoride (PMSF), $10 \mathrm{ng} / \mathrm{mL}$ leupeptin, and $10 \mu \mathrm{g} / \mathrm{mL}$ aprotinin). Volumes of extract containing equal amounts of proteins $(40 \mu \mathrm{g})$ were applied to SDS-PAGE gels, and resolved proteins were transferred to nitrocellulose membranes (Schleicher \& Schuell, Keene, NH, USA). The membranes were blocked with nonfat milk solution for $30 \mathrm{~min}$, then washed, and probed with primary antibody. Membranes were then rinsed with Tris-buffered saline containing $0.1 \%$ Tween 20 to remove unbound primary antibody, and incubated with horseradish peroxidase-conjugated secondary antibody for $2 \mathrm{~h}$. The membranes were rinsed again and developed using enhanced chemiluminescence (ECL) reagents (Amersham Biosciences, Piscataway, NJ, USA). The intensity of a protein band was quantified by Gel-pro analysis 3.1 software. The resultant values of protein expression were normalized to those of actin.

\subsection{Statistics}

All data are expressed as the mean \pm SD of three or more independent experiments. Comparison between groups was made by one-way analysis of variance (ANOVA) followed by an appropriate post-hoc test, such as LSD or $t$-test to analyze the difference. A value of $p<0.05$ was considered to be statistically significant.

Acknowledgments: Financial support is provided by grants from Tainan Municipal An-Nan Hospital-China Medical University (ANHRF103-12 and ANHRF104-10).

Author Contributions: M.-H.L. and P.J.C. conceived and designed the experiments; Y.-H.L., H.-L.C., H.-Y.C., and F.-H.J. performed the experiments; M.-H.L., Y.-H.L., and P.J.C. analyzed the data; P.J.C. wrote the paper.

Conflicts of Interest: The authors declare no conflict of interest.

\section{References}

1. Ferlay, J.; Soerjomataram, I.; Dikshit, R.; Eser, S.; Mathers, C.; Rebelo, M.; Parkin, D.M.; Forman, D.; Bray, F. Cancer incidence and mortality worldwide: Sources, methods and major patterns in globocan 2012. Int. J. Cancer 2015, 136, E359-E386. [CrossRef] [PubMed] 
2. Shang, P.F.; Kwong, J.; Wang, Z.P.; Tian, J.; Jiang, L.; Yang, K.; Yue, Z.J.; Tian, J.Q. Intravesical bacillus calmette-guerin versus epirubicin for Ta and T1 bladder cancer. Cochrane Database Syst. Rev. 2011. [CrossRef]

3. Wajant, H. The fas signaling pathway: More than a paradigm. Science 2002, 296, 1635-1636. [CrossRef] [PubMed]

4. $\quad$ Er, E.; Oliver, L.; Cartron, P.F.; Juin, P.; Manon, S.; Vallette, F.M. Mitochondria as the target of the pro-apoptotic protein bax. Biochim. Biophys. Acta 2006, 1757, 1301-1311. [CrossRef] [PubMed]

5. Jiang, X.; Wang, X. Cytochrome C-mediated apoptosis. Annu. Rev. Biochem. 2004, 73, 87-106. [CrossRef] [PubMed]

6. Heiden, M.G.V.; Thompson, C.B. Bcl-2 proteins: Regulators of apoptosis or of mitochondrial homeostasis? Nat. Cell Biol. 1999, 1, E209-E216. [CrossRef] [PubMed]

7. Lee, S.T.; Lu, M.H.; Chien, L.H.; Wu, T.F.; Huang, L.C.; Liao, G.I. Suppression of urinary bladder urothelial carcinoma cell by the ethanol extract of pomegranate fruit through cell cycle arrest and apoptosis. BMC Complement. Altern. Med. 2013, 13. [CrossRef] [PubMed]

8. Hu, G.H.; Zhang, L.; Rong, Y.F.; Ni, X.L.; Sun, Y.H. Downstream carcinogenesis signaling pathways by green tea polyphenols: A translational perspective of chemoprevention and treatment for cancers. Curr. Drug Metab. 2014, 15, 14-22. [CrossRef] [PubMed]

9. Raina, K.; Tyagi, A.; Kumar, D.; Agarwal, R.; Agarwal, C. Role of oxidative stress in cytotoxicity of grape seed extract in human bladder cancer cells. Food Chem. Toxicol. 2013, 61, 187-195. [CrossRef] [PubMed]

10. Bai, Y.; Mao, Q.Q.; Qin, J.; Zheng, X.Y.; Wang, Y.B.; Yang, K.; Shen, H.F.; Xie, L.P. Resveratrol induces apoptosis and cell cycle arrest of human T24 bladder cancer cells in vitro and inhibits tumor growthin vivo. Cancer Sci. 2010, 101, 488-493. [CrossRef] [PubMed]

11. Morré, D.J.; Chueh, P.J.; Morré, D.M. Capsaicin inhibits preferentially the nadh oxidase and growth of transformed cells in culture. Proc. Natl. Acad. Sci. USA 1995, 92, 1831-1835. [CrossRef] [PubMed]

12. Wang, H.M.; Chuang, S.M.; Su, Y.C.; Li, Y.H.; Chueh, P.J. Down-regulation of tumor-associated NADH oxidase, tNOX (ENOX2), enhances capsaicin-induced inhibition of gastric cancer cell growth. Cell Biochem. Biophys. 2011, 61, 355-366. [CrossRef] [PubMed]

13. Bu, H.Q.; Cai, K.; Shen, F.; Bao, X.D.; Xu, Y.; Yu, F.; Pan, H.Q.; Chen, C.H.; Du, Z.J.; Cui, J.H. Induction of apoptosis by capsaicin in hepatocellular cancer cell line SMMC-7721 is mediated through ROS generation and activation of JNK and p38 MAPK pathways. Neoplasma 2015, 62, 582-591. [CrossRef] [PubMed]

14. Pramanik, K.C.; Fofaria, N.M.; Gupta, P.; Ranjan, A.; Kim, S.H.; Srivastava, S.K. Inhibition of beta-catenin signaling suppresses pancreatic tumor growth by disrupting nuclear $\beta$-catenin/TCF-1 complex: Critical role of STAT-3. Oncotarget 2015, 6, 11561-11574. [CrossRef] [PubMed]

15. Lau, J.K.; Brown, K.C.; Dom, A.M.; Witte, T.R.; Thornhill, B.A.; Crabtree, C.M.; Perry, H.E.; Brown, J.M.; Ball, J.G.; Creel, R.G.; et al. Capsaicin induces apoptosis in human small cell lung cancer via the TRPV6 receptor and the calpain pathway. Apoptosis 2014, 19, 1190-1201. [CrossRef] [PubMed]

16. Ito, K.; Nakazato, T.; Yamato, K.; Miyakawa, Y.; Yamada, T.; Hozumi, N.; Segawa, K.; Ikeda, Y.; Kizaki, M. Induction of apoptosis in leukemic cells by homovanillic acid derivative, capsaicin, through oxidative stress: Implication of phosphorylation of p53 at ser-15 residue by reactive oxygen species. Cancer Res. 2004, 64, 1071-1078. [CrossRef] [PubMed]

17. Sanchez, A.M.; Malagarie-Cazenave, S.; Olea, N.; Vara, D.; Chiloeches, A.; Diaz-Laviada, I. Apoptosis induced by capsaicin in prostate PC-3 cells involves ceramide accumulation, neutral sphingomyelinase, and JNK activation. Apoptosis 2007, 12, 2013-2024. [CrossRef] [PubMed]

18. Lee, Y.S.; Kang, Y.S.; Lee, J.S.; Nicolova, S.; Kim, J.A. Involvement of NADPH oxidase-mediated generation of reactive oxygen species in the apototic cell death by capsaicin in HepG2 human hepatoma cells. Free Radic. Res. 2004, 38, 405-412. [CrossRef] [PubMed]

19. Zhang, R.; Humphreys, I.; Sahu, R.P.; Shi, Y.; Srivastava, S.K. In vitro andin vivo induction of apoptosis by capsaicin in pancreatic cancer cells is mediated through ROS generation and mitochondrial death pathway. Apoptosis 2008, 13, 1465-1478. [CrossRef] [PubMed]

20. Pramanik, K.C.; Boreddy, S.R.; Srivastava, S.K. Role of mitochondrial electron transport chain complexes in capsaicin mediated oxidative stress leading to apoptosis in pancreatic cancer cells. PLoS ONE 2011, 6, e20151. [CrossRef] [PubMed]

21. Kim, M.Y.; Trudel, L.J.; Wogan, G.N. Apoptosis induced by capsaicin and resveratrol in colon carcinoma cells requires nitric oxide production and caspase activation. Anticancer Res. 2009, 29, 3733-3740. [PubMed] 
22. Bhutani, M.; Pathak, A.K.; Nair, A.S.; Kunnumakkara, A.B.; Guha, S.; Sethi, G.; Aggarwal, B.B. Capsaicin is a novel blocker of constitutive and interleukin-6-inducible STAT3 activation. Clin. Cancer Res. 2007, 13, 3024-3032. [CrossRef] [PubMed]

23. Wang, H.M.; Chueh, P.J.; Chang, S.P.; Yang, C.L.; Shao, K.N. Effect of ccapsaicin on tNOX (ENOX2) protein expression in stomach cancer cells. Biofactors 2009, 34, 209-217. [CrossRef]

24. Mao, L.C.; Wang, H.M.; Lin, Y.Y.; Chang, T.K.; Hsin, Y.H.; Chueh, P.J. Stress-induced down-regulation of tumor-associated nadh oxidase during apoptosis in transformed cells. FEBS Lett. 2008, 582, 3445-3450. [CrossRef] [PubMed]

25. Chueh, P.J. Cell membrane redox systems and transformation. Antioxid. Redox Signal. 2000, 2, $177-187$. [CrossRef] [PubMed]

26. Chueh, P.J.; Wu, L.Y.; Morré, D.M.; Morré, D.J. Tnox is both necessary and sufficient as a cellular target for the anticancer actions of capsaicin and the green tea catechin (-)-epigallocatechin-3-gallate. Biofactors 2004, 20, 235-249. [PubMed]

27. Liu, S.C.; Yang, J.J.; Shao, K.N.; Chueh, P.J. Rna interference targeting tNOX attenuates cell migration via a mechanism that involves membrane association of Rac. Biochem. Biophys. Res. Commun. 2008, 365, 672-677. [CrossRef] [PubMed]

28. Lee, Y.H.; Chen, H.Y.; Su, L.J.; Chueh, P.J. Sirtuin 1 (SIRT1) deacetylase activity and NAD(+)/NADH ratio are imperative for capsaicin-mediated programmed cell death. J. Agric. Food Chem. 2015, 63, 7361-7370. [CrossRef] [PubMed]

29. Wang, Y.Q.; Cao, Q.; Wang, F.; Huang, L.Y.; Sang, T.T.; Liu, F.; Chen, S.Y. SIRT1 protects against oxidative stress-induced endothelial progenitor cells apoptosis by inhibiting FOXO3a via FOXO3a ubiquitination and degradation. J. Cell. Physiol. 2015, 230, 2098-2107. [CrossRef] [PubMed]

30. Wang, J.; Liu, S.; Yin, Y.; Li, M.; Wang, B.; Yang, L.; Jiang, Y. FOXO3-mediated up-regulation of Bim contributes to rhein-induced cancer cell apoptosis. Apoptosis 2015, 20, 399-409. [CrossRef] [PubMed]

31. Su, Y.C.; Lin, Y.H.; Zeng, Z.M.; Shao, K.N.; Chueh, P.J. Chemotherapeutic agents enhance cell migration and epithelial-to-mesenchymal transition through transient up-regulation of tNOX (ENOX2) protein. Biochim. Biophys. Acta 2012, 1820, 1744-1752. [CrossRef] [PubMed]

32. Liu, N.C.; Hsieh, P.F.; Hsieh, M.K.; Zeng, Z.M.; Cheng, H.L.; Liao, J.W.; Chueh, P.J. Capsaicin-mediated tNOX (ENOX2) up-regulation enhances cell proliferation and migration in vitro andin vivo. J. Agric. Food Chem. 2012, 60, 2758-2765. [CrossRef] [PubMed]

33. Lee, Y.S.; Kwon, E.J.; Jin, D.Q.; Park, S.H.; Kang, Y.S.; Huh, K.; Kim, J.A. Redox status-dependent regulation of cyclooxygenases mediates the capsaicin-induced apoptosis in human neuroblastoma cells. J. Environ. Pathol. Toxicol. Oncol. 2002, 21, 113-120. [CrossRef] [PubMed]

34. Amantini, C.; Ballarini, P.; Caprodossi, S.; Nabissi, M.; Morelli, M.B.; Lucciarini, R.; Cardarelli, M.A.; Mammana, G.; Santoni, G. Triggering of transient receptor potential vanilloid type 1 (TRPV1) by capsaicin induces Fas/CD95-mediated apoptosis of urothelial cancer cells in an ATM-dependent manner. Carcinogenesis 2009, 30, 1320-1329. [CrossRef] [PubMed]

35. Caprodossi, S.; Amantini, C.; Nabissi, M.; Morelli, M.B.; Farfariello, V.; Santoni, M.; Gismondi, A.; Santoni, G. Capsaicin promotes a more aggressive gene expression phenotype and invasiveness in null-TRPV1 urothelial cancer cells. Carcinogenesis 2011, 32, 686-694. [CrossRef] [PubMed]

36. Yang, Z.H.; Wang, X.H.; Wang, H.P.; Hu, L.Q.; Zheng, X.M.; Li, S.W. Capsaicin mediates cell death in bladder cancer T24 cells through reactive oxygen species production and mitochondrial depolarization. Urology 2010, 75, 735-741. [CrossRef] [PubMed]

37. Nakagawa, T.; Guarente, L. Sirtuins at a glance. J. Cell Sci. 2011, 124, 833-838. [CrossRef] [PubMed]

38. Vaziri, H.; Dessain, S.K.; Eagon, E.N.; Imai, S.I.; Frye, R.A.; Pandita, T.K.; Guarente, L.; Weinberg, R.A. Hsir2(SIRT1) functions as an NAD-dependent p53 deacetylase. Cell 2001, 107, 149-159. [CrossRef]

39. Luo, J.; Nikolaev, A.Y.; Imai, S.; Chen, D.; Su, F.; Shiloh, A.; Guarente, L.; Gu, W. Negative control of p53 by Sir2 $\alpha$ promotes cell survival under stress. Cell 2001, 107, 137-148. [CrossRef]

40. Chang, T.C.; Wentzel, E.A.; Kent, O.A.; Ramachandran, K.; Mullendore, M.; Lee, K.H.; Feldmann, G.; Yamakuchi, M.; Ferlito, M.; Lowenstein, C.J.; et al. Transactivation of miR-34a by p53 broadly influences gene expression and promotes apoptosis. Mol. Cell 2007, 26, 745-752. [CrossRef] [PubMed] 
41. Mohan, M.; Kumar, V.; Lackner, A.A.; Alvarez, X. Dysregulated miR-34a-SIRT1-Acetyl p65 axis is a potential mediator of immune activation in the colon during chronic simian immunodeficiency virus infection of rhesus macaques. J. Immunol. 2014. [CrossRef] [PubMed]

42. Lu, J.; Zhang, M.; Huang, Z.; Sun, S.; Zhang, Y.; Zhang, L.; Peng, L.; Ma, A.; Ji, P.; Dai, J.; et al. SIRT1 in $\mathrm{B}$ [a]P-induced lung tumorigenesis. Oncotarget 2015, 6, 27113-27129. [CrossRef] [PubMed]

43. Ishibe, S.; Joly, D.; Liu, Z.X.; Cantley, L.G. Paxillin serves as an ERK-regulated scaffold for coordinating FAK and Rac activation in epithelial morphogenesis. Mol. Cell 2004, 16, 257-267. [CrossRef] [PubMed]

44. Gao, Z.; Wang, H.; Xiao, F.J.; Shi, X.F.; Zhang, Y.K.; Xu, Q.Q.; Zhang, X.Y.; Ha, X.Q.; Wang, L.S. SIRT1 mediates Sphk1/S1P-induced proliferation and migration of endothelial cells. Int. J. Biochem. Cell Biol. 2016, 74, 152-160. [CrossRef] [PubMed]

45. Wu, Z.; Zeng, Y.; Zhong, M.; Wang, B. Targeting A549 lung adenocarcinoma cell growth and invasion with proteaseactivated receptor1 siRNA. Mol. Med. Rep. 2014, 9, 1787-1793. [PubMed]

46. Huang, S.; Chueh, P.J.; Lin, Y.W.; Shih, T.S.; Chuang, S.M. Disturbed mitotic progression and genome segregation are involved in cell transformation mediated by nano- $\mathrm{TiO}_{2}$ long-term exposure. Toxicol. Appl. Pharmacol. 2009, 241, 182-194. [CrossRef] [PubMed]

47. Kuo, Y.F.; Su, Y.Z.; Tseng, Y.H.; Wang, S.Y.; Wang, H.M.; Chueh, P.J. Flavokawain B, a novel chalcone from Alpinia pricei Hayata with potent apoptotic activity: Involvement of ROS and GADD153 upstream of mitochondria-dependent apoptosis in HCT116 cells. Free Radic. Biol. Med. 2010, 49, 214-226. [CrossRef] [PubMed]

Sample Availability: Samples of sitNOX are available from the authors.

(C) 2016 by the authors; licensee MDPI, Basel, Switzerland. This article is an open access article distributed under the terms and conditions of the Creative Commons Attribution (CC-BY) license (http:/ / creativecommons.org/licenses/by/4.0/). 